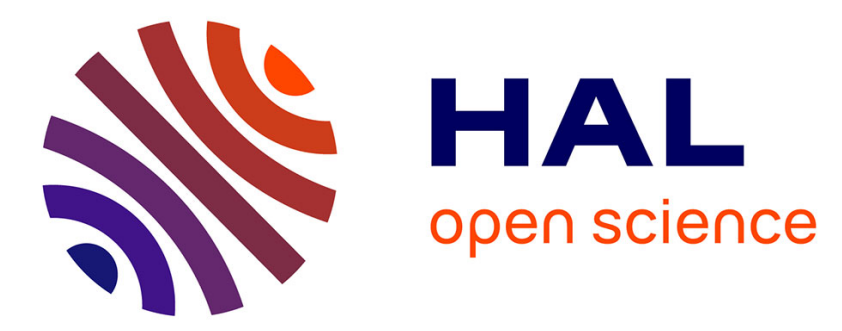

\title{
Relevance of age-related growth references: variations in body measurements among girls in relation to their menarche status
}

\author{
Anne-Madeleine Bau, Angelika Schaffrath Rosario, Susanna Wiegand, Peter \\ Martus, Liane Schenk
}

\section{To cite this version:}

Anne-Madeleine Bau, Angelika Schaffrath Rosario, Susanna Wiegand, Peter Martus, Liane Schenk. Relevance of age-related growth references: variations in body measurements among girls in relation to their menarche status. Journal of Public Health, 2010, 19 (3), pp.215-222. 10.1007/s10389-0100381-3 . hal-00594458

\section{HAL Id: hal-00594458 \\ https://hal.science/hal-00594458}

Submitted on 20 May 2011

HAL is a multi-disciplinary open access archive for the deposit and dissemination of scientific research documents, whether they are published or not. The documents may come from teaching and research institutions in France or abroad, or from public or private research centers.
L'archive ouverte pluridisciplinaire HAL, est destinée au dépôt et à la diffusion de documents scientifiques de niveau recherche, publiés ou non, émanant des établissements d'enseignement et de recherche français ou étrangers, des laboratoires publics ou privés. 
Title: Relevance of age-related growth references: Variations in body measurements among girls in relation to their menarche status

Short title: Body measurements among adolescent girls

\author{
Authors: Anne-Madeleine Bau ${ }^{1}$, Angelika Schaffrath Rosario ${ }^{2}$, Susanna Wiegand ${ }^{1}$, Peter Martus ${ }^{3}$, Liane \\ Schenk $^{4}$ \\ ${ }^{1}$ Institute for Experimental Pediatric Endocrinology, Charité University Medicine Berlin \\ ${ }^{2}$ Robert Koch-Institute, Berlin \\ ${ }^{3}$ Institute for Biostatistic und Clinical Epidemiology, Charité University Medicine Berlin \\ ${ }^{4}$ Institute for Medicine Sociology, Charité University Medicine Berlin
}

\title{
Corresponding author:
}

Anne-Madeleine Bau, MSc, MPH

Charite-University-Medicine Berlin

Augustenburgerplatz 1

13353 Berlin - Germany

Tel: ++49 (0)30450666 217

Fax: ++49(0)30450566926

e-mail: anne-madeleine.bau@ charite.de

\section{Abstract}

Aim: The objective of this study is to fill the information gap by providing detailed information on the development of girls' BMI and hip and waist circumferences in correlation with their menarche status and to examine the impact of considering menarcheal age in addition to numerical age in the assessment of overweight and abdominal overweight.

Subjects and Methods: The description of data is based on two recently conducted cross-sectional surveys: the German Health Interview and Examination Survey for Children and Adolescents (KiGGS, n=1,942) and the Berlin School Children's Cohort (BSCOC, $\mathrm{n}=1,606)$. Anthropometric data are presented stratified by age in years (11-14) and menarche status. The frequency distribution of overweight and abdominal overweight was calculated according to German reference data. Group comparisons were performed with non-parametric tests.

Results: Changes regarding body composition occur mainly during pre-menarche and menarche. In girls in whom menarche had occurred more than 6 months ago, waist circumference and, to a lesser extent, BMI attained stable values, while the values for hip circumference were higher in post-menarche girls. The frequency distribution of overweight and abdominal overweight among post-menarche girls shows that they are more than twice as likely to be overweight and/or abdominally overweight as pre-menarche girls within the same age group.

Conclusion: The frequency distribution of overweight and abdominal overweight among girls in a similar age group but with a different menarche status demonstrates that misclassification of girls can arise when only age is taken into account. The progress of maturation is an important factor in assessing the growth and health of adolescents. 
Key words: BMI, waist circumference, hip circumference, menarche, adolescent girls 


\section{Introduction}

Children's growth and body development vary during their lifetimes, and age-based percentiles for body measurements are known and described in many studies (Kromeyer-Hauschild et al. 2001 and 2008; Fredriks et al. 2003 and 2005; Moreno et al. 1999; Stolzenberg et al. 2007; Kurth et al. 2007; Tanner et al. 1966; Cole 2000). Variations in development start at birth (sex-dimorphism). During puberty, body measurements and composition, as well as growth velocity, change significantly throughout the various biological development stages (Marshal and Tanner 1969; Cole 2003).

Therefore the World Health Organisation Expert Committee recommends that maturational status should be taken into account when interpreting anthropometric data based on chronological age (de Onis and Habicht 1996). In addition, pubertal body measurements are important as they are linked directly to the possible onset of metabolic cardiovascular chronic disease later in life (Jordan et al. 2005; Lakshman et al. 2008). Studies have shown that the risk factors of fat patterning are difficult to detect in childhood and are seen only after sexual maturation (Freedman et al. 1999). Waist circumference as a sign of central fat accumulation, rather than BMI, has come into the focus to characterize fat frequency distribution (McCarthy et al. 2008). In Europe there are comparatively few population studies on maturational status and anthropometric data during puberty. The main reason for this is that it is difficult to assess puberty age and to measure anthropometric data close to the puberty event. Therefore this study has two main aims: first, to fill the information gap by providing detailed information on the development of subjects' BMI and hip and waist circumferences in correlation with their pubertal stage (respectively three menarche stages: pre-menarche, recent menarche and post-menarche); and secondly, to determine the impact of considering menarcheal age in addition to numerical age when defining overweight / obesity and abdominal overweight ("overwaist"). The description of data and comparison are based on two cross-sectional surveys recently conducted in Germany. 


\section{Methods}

Sub-samples of 11- to 14-year-old girls were selected from two surveys: the nationwide representative German Health Interview and Examination Survey for Children and Adolescents (KiGGS), conducted by the Robert Koch-Institute (RKI) from 2003 to 2006 (Kurth et al. 2008); and the Berlin School Children's Cohort (BSCOC), performed by the Institute for Experimental Paediatric Endocrinology of Charité University Medicine 2006-2007 (Bau et al. 2009).

1,942 KiGGS girls were extracted from 17,641 children and adolescents (age range 0-17 years). This sample was then compared with 1,606 BSCOC girls, extracted from 1,842 girls between 10 and 16 years of age. KiGGS recruited the participants in two steps: first, 167 study locations (sample points) were chosen; then subjects were randomly selected from the official registers of local residents. The response rate was $66.6 \%$. BSCOC is a school study in Berlin. In selecting schools, the various school types, migration background and social structure in the city were all taken into consideration. 1,842 (40.8\%) girls agreed to participate. Both studies were approved by the local ethics committee.

Anthropometric measurements in both studies were performed by trained nurses. Girls' height and weight were measured in underwear with calibrated scales and stadiometers. Body Mass Index (BMI) and BMI standard deviation score (SDS) were calculated according to German reference data (Kromeyer-Hauschild et al. 2001). Girls over 1.4 BMI-SDS were classified as overweight; those between 1.4 and (-)1.4 BMI-SDS were classified as having normal weight; and those under -1.4 BMI-SDS were considered underweight. Waist circumference was measured with an inelastic measuring tape over the bare skin at the narrowest point between the lowest rib and the top of the iliac crest (Stolzenberg et al. 2007). Waist standard deviation score (waist-SDS) was calculated according to German reference data (Kromeyer-Hauschild et al. 2008). Girls over 1.3 waist-SDS, as recommended by Fredriks et al. (2005), were classified as abdominally overweight ("overwaist"); those between 1.3 and (-)1.3 waist-SDS were classified as having a normal waist; and those under -1.3 waist-SDS were considered abdominally underweight ("underwaist"). Hip circumference was measured over underwear over the great trochanters and at the widest circumference. The circumference was noted to the nearest $0.1 \mathrm{~cm}$ in KiGGS and $0.5 \mathrm{~cm}$ in BSCOC.

In both studies the sexual maturity of the girls was determined in an interview regarding their first menstrual period (menarche). KiGGS used the status-quo method (Kahl et al. 2007), asking girls simply whether they had or had not reached menarche. The menarche status was thus defined as pre-menarche or post-menarche. This method is also used in most of the current epidemiological studies concerning menarche status (Kaplowitz et al. 2001; Himes et al. 2009). Mean menarcheal age was calculated by means of a logit -analysis (Kahl et al. 2007). The KiGGS data is stratified in pre-menarche $(\mathrm{n}=913,47.0 \%)$ and post-menarche $(\mathrm{n}=1,029,53.0 \%)$ girls.

In BSCOC, in contrast, age at menarche was calculated from each girl's birthday and month and year of occurrence of the first menstruation (Koo and Rohan 1997, Bau et al. 2009). The girls were asked to recall the age at or the date of occurrence of their first menstruation. More than $50 \%$ of the girls were able to remember the month and the year of their menarche exactly. For those girls who could not exactly remember, the date was narrowed by seasonal calendar. This retrospective assessment method made it possible to stratify menarche 
status into pre-menarche, recent menarche (menarche reached $\leq$ six months ago) and post-menarche (menarche reached more than 6 months ago). The anthropometric data of girls who reached menarche within the last 6 months are comparable with data from longitudinal surveys, since the assessment interval is also between 3 and 6 months in longitudinal studies (Siervogel et al. 2003). The BSCOC data is presented separately for premenarche $(n=712,44.4 \%)$, recent menarche $(n=231,14.4 \%)$ and post-menarche $(n=661,41.2 \%)$ girls.

The two studies are comparable regarding sample size and mean age distribution; they differ in terms of migration background (Schenk et al. 2007), school type attendance, weight status and abdominal overweight. This variance is attributable to the difference in regions studied, Germany and Berlin respectively. Nevertheless, the anthropometric measurements of median weight, height, and waist and hip circumference of pre-menarche girls are comparable. An overview of the two sub-samples, KiGGS and BSCOC, is presented in Table 1.

\section{Please insert Table 1 here}

All data analysis was performed using SPSS Version 17.0. All anthropometric data are presented stratified by study, menarche status and age. Group comparisons were performed by means of a non-parametric test to evaluate differences between menarche stages and age groups with respect to median BMI and waist and hip circumferences (Mann-Witney-Test, M-W, and Kruskal-Wallis-Test, K-W). The level of significance was 0.05 (two-sided) for all statistical tests.

\section{Results}

The median BMI and waist and hip circumferences, stratified by menarche status and age group, are presented in Table 2 for the KiGGS girls; the same information for the BSCOC girls is presented in Table 3. The KiGGS results show that girls similar in age but at different menarche stages have different body measurements. Postmenarche girls have a higher median BMI (about 2-3 kg/m²) and a larger median waist circumference (about 4-5 $\mathrm{cm}$ ) and hip circumference (about $8-10 \mathrm{~cm}$ ) than girls who are not yet menstruating. With regard to girls at the same menarche stage but in different age groups, KiGGS data show that median hip circumference, (as well as height and weight - data not shown) is significantly higher in older age groups $(\mathrm{K}-\mathrm{W} \mathrm{p}<0.001)$, among both premenarche girls (about $4-5 \mathrm{~cm}$ ) and post-menarche girls (about 2-3 cm). This also holds for median waist circumference in pre-menarche girls (about $1 \mathrm{~cm}$ ), but not for waist circumference in post-menarche girls, and not for median BMI in either pre- or post-menarche girls.

\section{Please insert Table 2 here}

The BSCOC results (Table 3) allow for further differentiation. Girls similar in age but at different menarche stages: Recent menarche girls have a higher median BMI (about 2-3 kg/m²), and larger median waist (about 3-4 $\mathrm{cm}$ ) and hip circumferences (about $4-5 \mathrm{~cm}$ ) than girls who are not yet menstruating. Post-menarche girls (menarche more than six months ago) have a median hip circumference that is significantly higher (about 3-4 $\mathrm{cm}$ ) than in recent menarche girls; waist circumference, however, is not significantly higher. In general the differences from pre-menarche to recent menarche are greater than those from recent menarche to post- 
menarche, and the latter tend to increase with age. For girls at the same menarche stage but in different age group shows that BSCOC girls have the same median BMI, waist circumference and hip circumference, irrespective of their age, with the exception of hip circumference of pre-menarche girls.

\section{Please insert Table 3 here}

Table 2 (KiGGS) and Table 3 (BSCOC) also show the $10^{\text {th }}$ and $90^{\text {th }}$ percentiles for BMI, waist and hip circumference, which are the supposed limits for general underweight and overweight respectively. Figure 1 presents the frequency distribution of overweight; Figure 2 presents the frequency distribution of overwaist stratified by study, menarche status and age. The prevalence of overweight is about twice as high in postmenarche girls as in pre-menarche girls regardless of age. The prevalence of overweight is lower in older age groups when girls of the same menarche status are compared.

\section{Please insert Figure 1 here}

This frequency distribution is analogous for overwaist (Figure 2). Girls at the onset of menarche (see BSCOC data, Figure 2) are less overwaist than post-menarche girls who had their first menstruation more than six months ago. The frequency distribution of overwaist is in general higher than overweight.

\section{Please insert Figure 2 here}

\section{Discussion}

For the first time representative body measurements comprising median BMI and waist and hip circumferences and stratified for menarche status for German female adolescents (KiGGS) are available. The stratification of anthropometric measurements shows that girls similar in age who have not yet reached menarche have significantly lower BMI and hip and waist circumferences, while girls who have recently experienced menarche (BSCOC) show higher BMI and hip and waist circumference. The observation of higher data is comparable also for post menarche girls with exception of waist circumference (BSCOC girls) in comparison to recent menarche. With regard to girls at the same menarche stage but in different age groups, BMI and waist circumference show stable values in girls whose menarche occurred recently and more than six months ago. The analysis demonstrates that puberty changes affecting body composition (expressed by BMI and waist circumference) occur mainly during pre-menarche and menarche; few changes appear more than six months after menarche.

Neither the German anthropometric reference data (Kromeyer-Hauschild et al. 2001, Schaffrath Rosario et al. 2010) nor the reference data in Europe take menarche status into account. These reference data show a positive correlation between body measurements and age. The data presented here show no or only a weak correlation with age, but reveal significant differences in body measurements by considering menarcheal status. These results have two possible implications.

First, in view of the general anthropometric reference data, it seems we are more likely to misclassify girls with an early menarche as overweight if their menarche status is not factored in. A look at the $90^{\text {th }}$ BMI percentile of 
the twelve-year-old post-menarche KiGGS girls shows that the limit is set at $27.3 \mathrm{~kg} / \mathrm{m}^{2}$ (Table 2), whereas the German reference is 22.48 (Kromeyer-Hauschild et al. 2001). These trends decrease with age because the stable values of BMI and waist circumference in post-menarche girls become more in line with the average anthropometric reference data as they grow older.

On the other hand, the observation may simply further illustrate the secular trend of overweight and abdominal overweight over the last 20 years; thus, the percentiles are higher in the younger populations studied in KiGGS and BSCOC. But even if we consider the secular trend in overweight, the development gap among girls in the same age group but at different menarche stages is obvious.

Unfortunately we cannot observe the long-term development of the girls, and we have an age limitation of 11-14 years. Nevertheless, the (BSCOC) data also seems to implicate that the differentiation of body shape after menarche is of particular importance. Kromeyer-Hauschild et al. (2008) show that waist circumference increases between the age of 6 and 13 years and changes only slightly after this age. These waist circumference variations can also be observed in BSCOC. From pre-menarche to recent menarche, the difference is an average of $4-5 \mathrm{~cm}$, while the increase from recent menarche to post-menarche is on average only $1-2 \mathrm{~cm}$. The hip circumference is still higher with time elapsed after menarche. This means that the "female body shape" becomes more obvious and, consequently, BMI might also continue to increase slightly with time elapsed after menarche. The data imply that girls reach their individual waist circumference with post-menarche - a median value of $68 \mathrm{~cm}$ and a $90^{\text {th }}$ percentile of $80 \mathrm{~cm}$. Maffeis et al. (2001) observed that children with a waist circumference greater than the $90^{\text {th }}$ percentile are more likely to have multiple risk factors than children with a waist circumference less than the $90^{\text {th }}$ percentile, and that waist circumference is a better predictor of cardiovascular diseases risk factors than BMI (Savva et al. 2000; Csábi et al. 2000). Therefore, health professionals should incorporate the use of waist circumference measurements in their routine clinical examination of adult patients (cut-off point $\geq 80 \mathrm{~cm}$ for women) (Dobbelsteyn et al. 2001) and also for adolescents (Kromeyer-Hauschild et al. 2008; Fredriks et al. 2005; Moreno et al. 1999 and 2002; McCarthy et al. 2008). The cut-off point is not yet set for children and adolescents, but according to the results presented here, the $90^{\text {th }}$ percentile of post-menarche girls is close to 80 $\mathrm{cm}$. Moreno et al. (1999) have called for more research to establish adequate age-specific and gender-specific cut-off-points for reasons of health promotion and clinical practicality.

The strength of the BSCOC study is that it demonstrates variations in body measurements over time, especially those of girls who have already experienced menarche. The comparison of the two data sets performed in this study reveals that changes in body composition occur mainly during pre-menarche and recent menarche, and that few changes appear in the post-menarche phase; this is especially true for waist circumference. The frequency distribution of overweight and abdominal overweight among girls in similar age groups but at different menarche stages demonstrates that misclassification of girls can arise. Evaluation of menarche or the progress of maturation is important for assessing the growth and health of adolescents. 


\section{Acknowledgements}

The authors would like to express their highest gratitude to the participating girls and their parents, teachers and schools. Special thanks go to all the partners who were helpful in their critical discussions, especially Dr. Heidrun Kahl (Robert Koch-Institute, retired). The BSCOC study (Berlin School Children's Cohort) was funded by the EU FP 6 Network of Excellence "Environmental and endogenous factors influencing puberty onset. Programming effects of early nutrition on long-term health" 2005 - 2008 reference no. 513991 (PIONEER Puberty onset - influence of environmental and endogenous regulators). We would like to thank Prof. Dr. Heiko Krude, team leader of the research project, for granting us access to the data set. The KiGGS study was financed by the German Ministry of Health, the Ministry of Education and Research, and the Robert Koch Institute.

\section{Conflict of interest}

There is no conflict of interest that could be perceived as prejudicing the impartiality of the research reported.

\section{References}

Bau AM, Ernert A, Schenk L, Wiegand S, Martus P, Grüters A, Krude H (2009) Is there a further acceleration in the age at onset of menarche? A cross-sectional study in 1840 school children focusing on age and bodyweight at the onset of menarche. Eur J Endocrinol 160:107-113

Cole TJ (2000) Secular trends in growth. Proc Nutr Soc 59:317-324

Cole TJ (2003) The secular trend in human physical growth: a biological review. Econ Hum Biol 1:161-168

Csábi G, Török K, Jeges S, Molnár D (2000) Presence of metabolic cardiovascular syndrome in obese children. Eur J Pediatr 159:91-94

de Onis M, Habicht JP (1996) Anthropometric reference data for international use: recommendations from a World Health Organization Expert Committee. Am J Clin Nutr 64:650-658

Dobbelsteyn CJ, Joffres MR, MacLean DR, Flowerdew G (2001) A comparative evaluation of waist circumference, waist-to-hip ratio and body mass index as indicators of cardiovascular risk factors. The Canadian Heart Health Surveys. Int J of Obes 25:652-661

Fredriks AM, van Buuren S, Jeurissen S, Fekker FW, Verloove-Vanhorick SP, Wit JM (2003) Height, weight, body mass index and pubertal development reference values for children of Turkish origin in the Netherlands. Eur J Pediatr 162:788-793

Fredriks AM, van Buuren S, Fekkes M, Verloove-Vanhorick SP, Wit JM (2005) Are age references for waist circumference, hip circumference and waist-hip ratio in Dutch children useful in clinical practice? Eur J Pediatr 164:216-222

Freedman D, Serdula M, Srinivasan S, Berenson G (1999) Relation of circumference and skinfold thicknesses to lipid and insulin concentrations in children and adolescents: the Bogalusa Heart Study. Am J Clin Nutr 69: 308-317

Himes JH, Park K, Styne D (2009) Menarche and assessment of body mass index in adolescent girls. J Pediatr 155:393-397

Jordan SJ, Webb PM, Green AC (2005) Height, age at menarche, and risk of epithelial ovarian cancer. Cancer Epidemiol Biomakers Prev 14:2045-2048

Kahl H, Schaffrath Rosario A, Schlaud M (2007) Sexuelle Reifung von Kindern und Jugendlichen in 
Deutschland. Ergebnisse des Kinder- und Jugendgesundheitssurvey. BundesgesundheitsblattGesundheitsforschung-Gesundheitsschutz 50:677-685

Kaplowitz P, Slora E, Wassermann R, Pedlow St, Herman-Giddens M (2001) Earlier onset of puberty in girls: Relation to increased body mass index and race. Pediatr 108:347-353

Koo MM, Rohan TE (1997) Accuracy of short-term recall of age at menarche. Ann Hum Biol 24:61-64

Kromeyer-Hauschild K, Wabitsch M, Kunze D, Geller F, Geiß HC, Hesse V, Hippel vA, Jaeger U, Johnsen D, Korte, W, Menner K, Müller G, Müller JM, Niemann-Pilatus A, Remer T, Schaefers F, Wittchen HU, Zabransky S, Zellner K, Ziegler A, Hebebrand J (2001) Perzentile für den Body-Mass-Index für das Kindesund Jugendalter unter Heranziehung verschiedener deutscher Stichproben. Monatsschr Kinderheilkd149:807818

Kromeyer-Hauschild K, Gäßler N, Zellner K (2008) Perzentile für den Taillenumfang von Jenaer Kindern im Alter von 6 bis 18 Jahren. Aktuel Ernahrungsmed 33:116-122

Kurth BM, Schaffrath Rosario A (2007) Die Verbreitung von Übergewicht und Adipositas bei Kindern und Jugendlichen in Deutschland. Ergebnisse des Kinder- und Jugendgesundheitssurvey. Bundesgesundheitsblatt-Gesundheitsforschung-Gesundheitsschutz 50:736-743

Kurth B-M, Kamtsiuris P, Hoelling H, Schlaud M, Dölle R, Ellert U et al. (2008) The challenge of comprehensively mapping children's health in a nation-wide health survey: design of the German KiGGSStudy. BMC Public Health 8:196-204

Lakshman R, Forouhi N, Luben R, Bingham S, Khaw K, Wareham N, Ong KK (2008) Association between age at menarche and risk of diabetes in adults: results from EPIC Norfolk cohort study. Diabetologia 51:781-786

Maffeis C, Pietrobelli A, Grezzani A, Provera S, Tatò L (2001) Waist circumference and cardiovascular risk factors in prepubertal children. Obes Res 9:179-177

Marshal W, Tanner J (1969) Variations in the pattern of pubertal changes in girls. Arch Dis Child 44:291-303.

McCarthy HD, Ellis SM, Cole TJ (2008) Central overweight and obesity in British youth aged 11-16 years: cross sectional surveys of waist circumference. BMJ 326:624-630

Moreno LA, Fleta J, Mur L, Rodriguez G, Sarria A, Bueno M (1999) Waist circumference values in Spanish children - Gender related differences. Eur J Clin Nutr 53:429-433

Moreno LA, Pineda I, Rodriguez G, Fleta J, Sarria A, Bueno M (2002) Waist circumference for the screening of the metabolic syndrome in children. Acta Pediatr 91:1307-1312

Savva SC, Tornaritis M, Savva ME et al (2000) Waist circumference and waist-to-height razio are better predictors of cardiovascular disease risk factors in children than body mass index. Int J Obes 24:1453-1458

Schaffrath Rosario A, Kurth BM, Stolzenberg H, Ellert U, Neuhauser H (2010): Body mass index percentiles for children and adolescents in Germany based on a nationally representative sample (KiGGS 2003-2006). European Journal of Clinical Nutrition, 64, 341-349.

Schenk L, Ellert U, Neuhauser H (2007) Kinder und Jugendliche mit Migrationshintergrund in Deutschland. Methodische Aspekte im Kinder- und Jugendgesundheitssurvey (KIGGS). BundesgesundheitsblattGesundheitsforschung-Gesundheitsschutz. 50:590-599

Siervogel RM, Demerath EW, Schubert Ch, Remsberg KE, Chumlea WC, Sun S, Czerwinski St, Towne B (2003) Puberty and Body Composition. Horm Res 60(Suppl 1):S36-S45

Stolzenberg H, Kahl H, Bergmann KE (2007) Body measurements of children and adolescents in Germany. Results of the German Health Interview and Examination Survey for Children and Adolescents (KiGGS). 
Bundesgesundheitsblatt-Gesundheitsforschung-Gesundheitsschutz 50:659-669

Tanner JM, Whitehouse RH, Takaiski M (1966) Standards from birth to maturity, for height, weight, height velocity and weight velocity: British children 1965. Arch Dis Child 41:454-462 
Figure 1: Frequency distribution (\%) of under-, normal- and overweight in KiGGS and BSCOC data (according to German reference Kromeyer-Hauschild et al. 2001) similar in age group but at different menarche stages

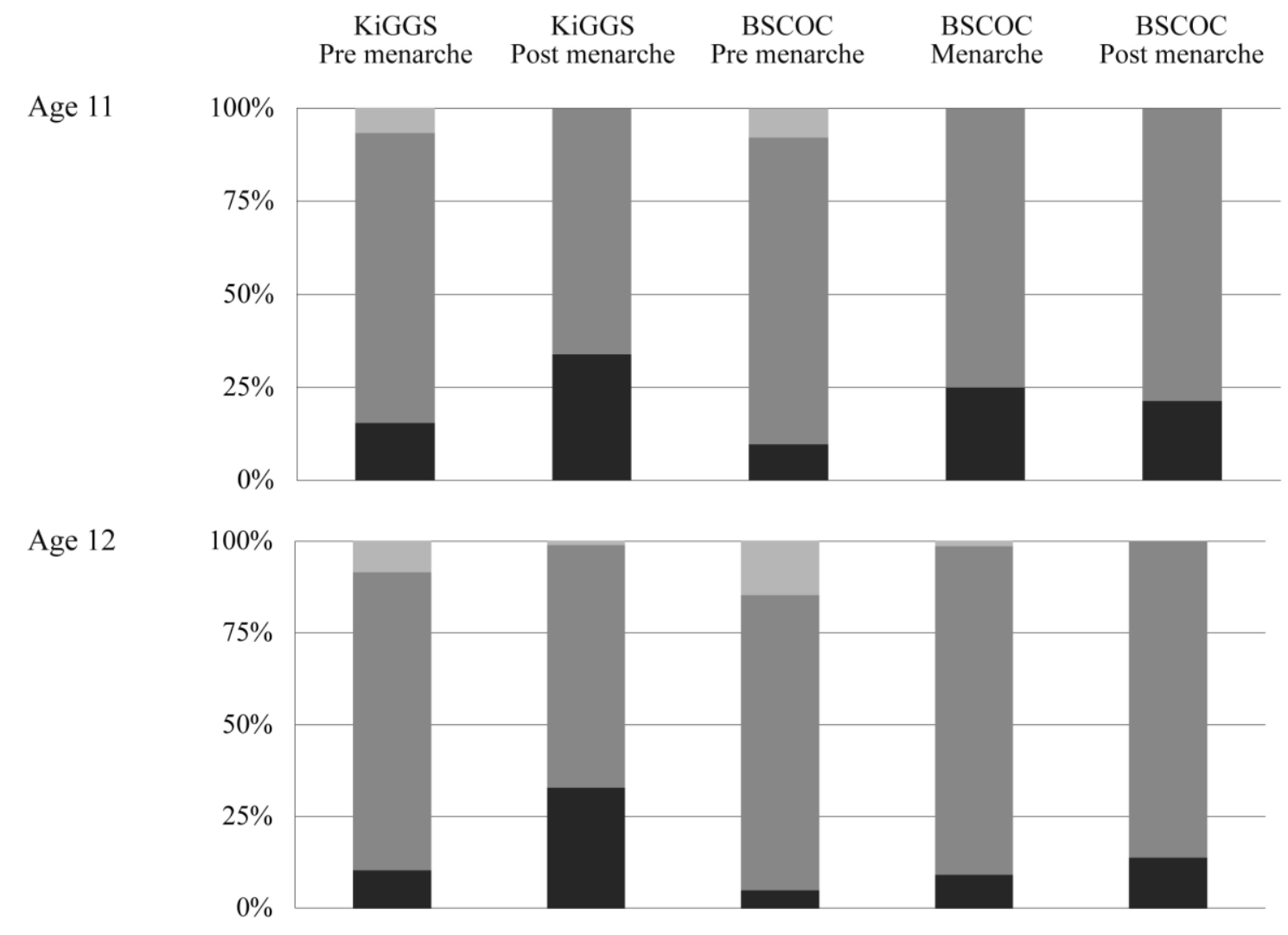

Age 13

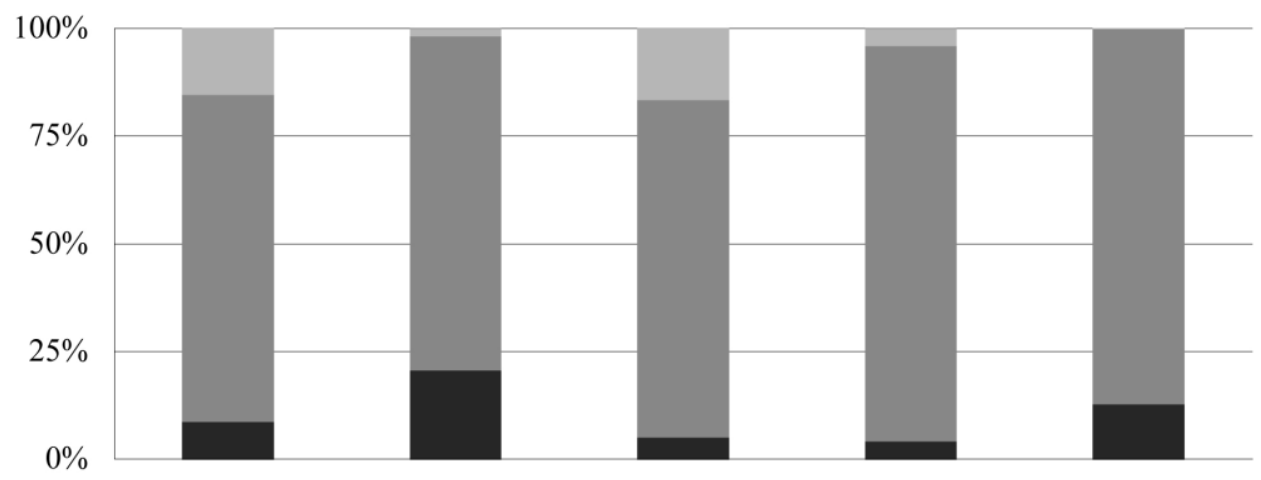

Age 14

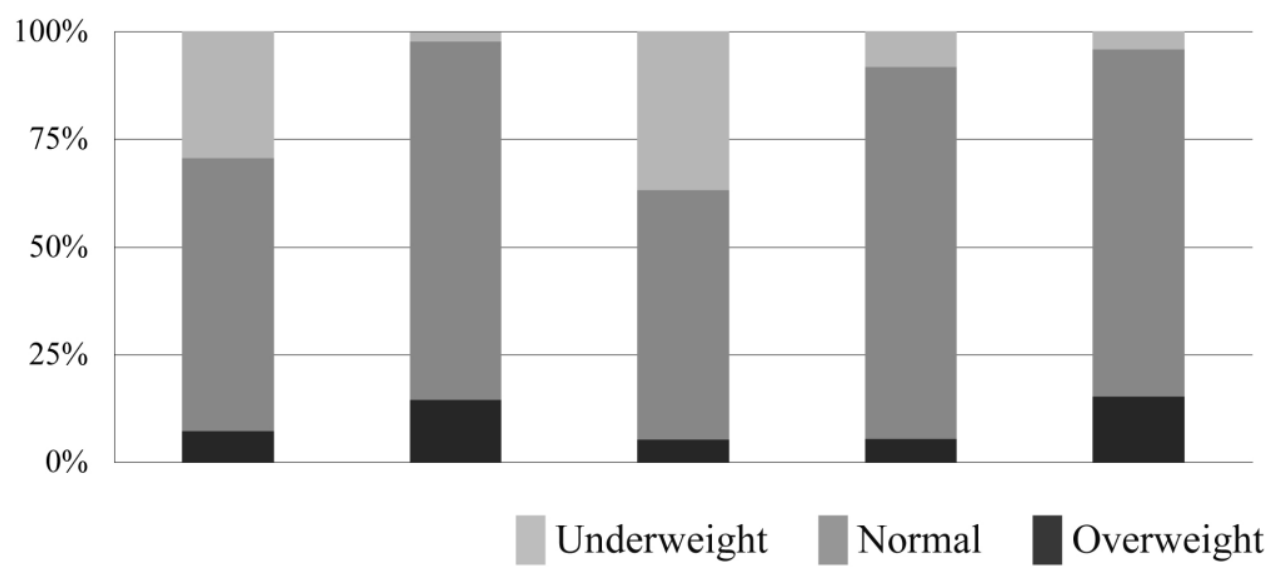


Figure 2: Frequency distribution (\%) of under-, normal- and overwaist in KiGGS and BSCOC data (according to German reference Kromeyer-Hauschild et al. 2008) similar in age group but at different menarche stages

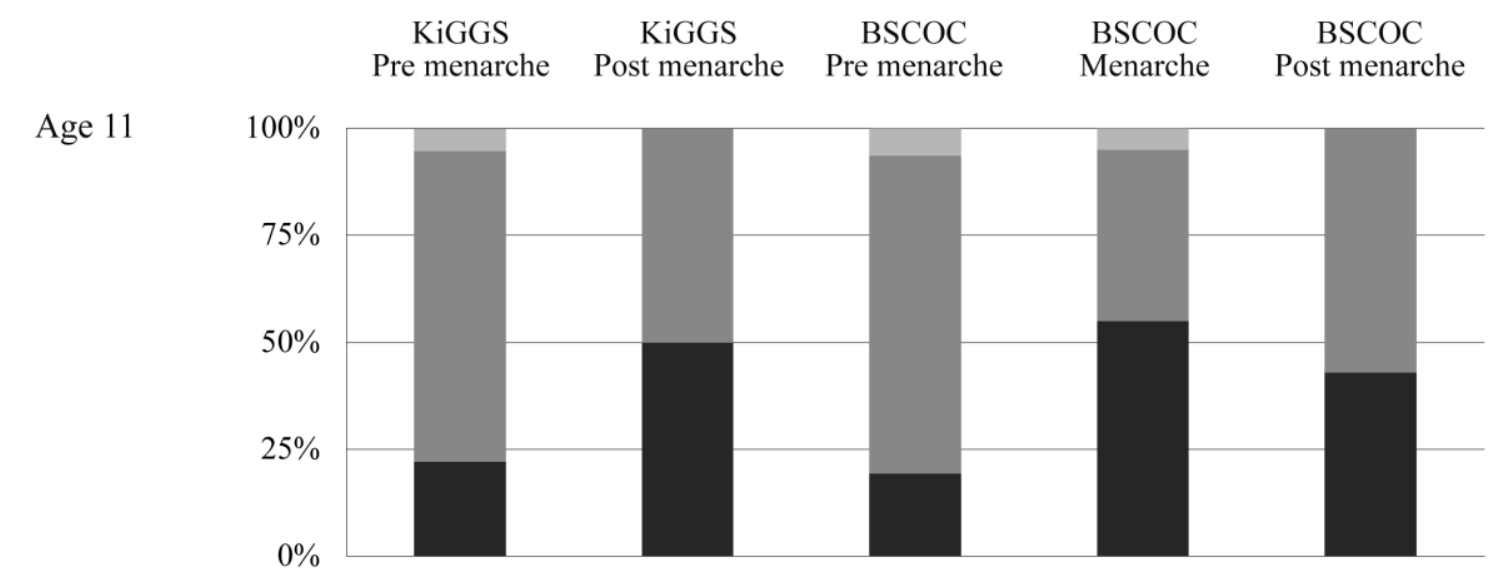

Age 12

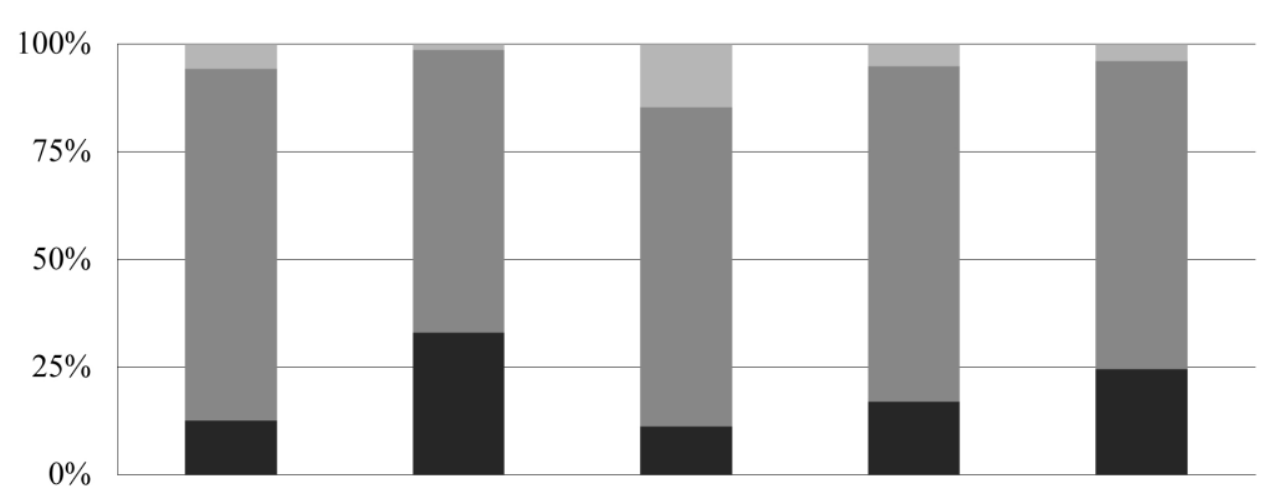

Age 13

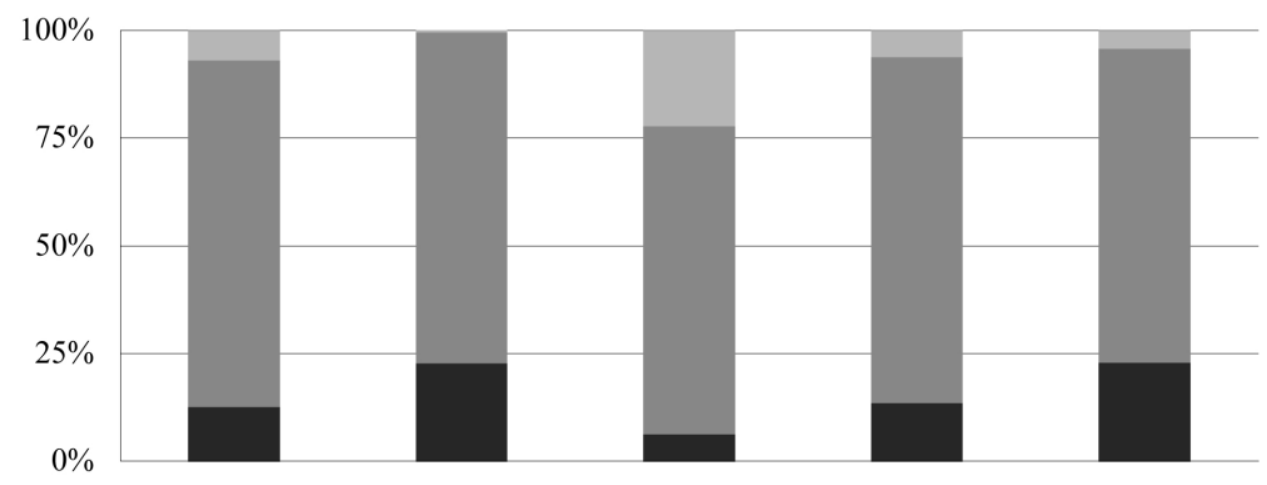

Age 14

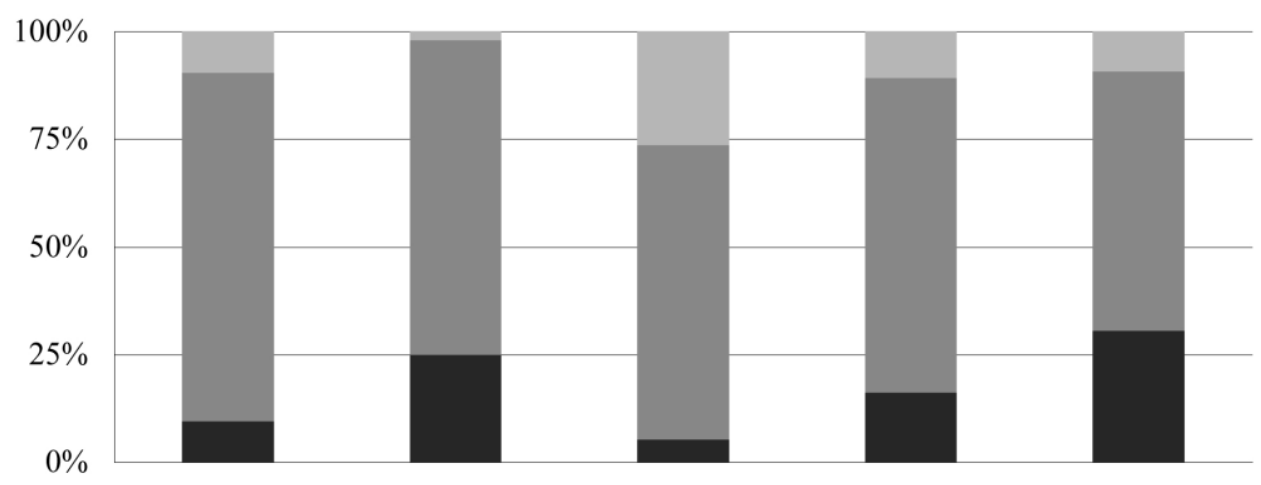

Underwaist Normal Overwaist

Statistically significant difference $(\mathrm{p}<0.001)$ in frequency distribution of under-, normal- and overwaist according to menarche status of KiGGS and BSCOC data 
Table 1: Frequency distribution of age, migration background and school type attendance of studied populations, KiGGS and BSCOC

\begin{tabular}{lcc}
\hline Characteristics, 11-14 years old & KiGGS girls & BSCOC girls \\
& N=1,606 \\
\hline Age (mean, SD) & $13.1(1.2)$ & $13.0(1.0)$ \\
Migration background (\%) & 78.6 & 63.4 \\
None & 6.1 & 9.1 \\
One-sided & 15.3 & 27.5 \\
Two-sided & & \\
School type (\%) & 8.9 & 20.9 \\
Primary school/ Grundschule & 17.2 & 4.2 \\
Secondary general school/ Hauptschule und Sonderschule & 28.2 & 16.5 \\
Intermediate secondary school/ Realschule & 9.0 & 14.6 \\
Comprehensive school/ Gesamtschule & 36.7 & 43.8 \\
Grammar school/ Gymnasium & $12.8(12.8-12.9)^{*}$ & $12.8(12.75-12.9)^{* *}$ \\
Menarche age in years (mean and 95\%CI) & &
\end{tabular}

* Kahl H, Schaffrath Rosario A, Schlaud M (2007) Sexuelle Reifung von Kindern und Jugendlichen in Deutschland. Ergebnisse des Kinder- und Jugendgesundheitssurvey. Bundesgesundheitsblatt-Gesundheitsforschung-Gesundheitsschutz 50:677-685

** Bau AM, Ernert A, Schenk L, Wiegand S, Martus P, Grüters A, Krude H (2009) Is there a further acceleration in the age at onset of menarche? A cross-sectional study in 1840 school children focusing on age and bodyweight at the onset of menarche. Eur J Endocrinology 160:107-113 
Table 2: KiGGS data: BMI and waist and hip circumferences (median; 10; 90 percentile) according to pre- and post- menarche per age group

\begin{tabular}{|c|c|c|c|c|c|}
\hline & $\mathrm{N}$ & $\begin{array}{l}\text { Pre-Menarche } \\
\text { (median; } 10 ; 90 \text { percentile) }\end{array}$ & $\mathrm{N}$ & $\begin{array}{l}\text { Post-Menarche } \\
\text { (median; } 10 ; 90 \text { percentile) }\end{array}$ & $\begin{array}{l}\text { P-value } \\
\hookleftarrow\end{array}$ \\
\hline \multicolumn{6}{|c|}{ BMI (kg/m2) } \\
\hline$\overline{11}$ & 459 & $18.0(15.2 ; 23.5)$ & 53 & $21.1(17.9 ; 26.7)$ & $* *$ \\
\hline 12 & 282 & $18.4(15.5 ; 23.2)$ & 210 & $20.6(17.4 ; 27.3)$ & $* *$ \\
\hline 13 & 129 & $18.0(15.6 ; 23.5)$ & 341 & $20.6(17.5 ; 25.9)$ & $* *$ \\
\hline 14 & 41 & $17.9(15.6 ; 23.7)$ & 420 & $20.9(18 ; 26)$ & $* *$ \\
\hline $\mathrm{P}$-value î & & n.s. & & n.s. & \\
\hline \multicolumn{6}{|c|}{$\begin{array}{l}\text { Waist circumference }(\mathrm{cm}) \\
\end{array}$} \\
\hline 11 & 456 & $62.0(55.7 ; 74.8)$ & 54 & $68.0(59.8 ; 81.2)$ & $* *$ \\
\hline 12 & 279 & $63.2(57.4 ; 72.9)$ & 209 & $67.7(60.8 ; 82.1)$ & $* *$ \\
\hline 13 & 128 & $62.9(58.5 ; 77.2)$ & 340 & $67.5(61.2 ; 79.2)$ & $* *$ \\
\hline 14 & 42 & $63.1(58.5 ; 72.6)$ & 420 & $67.8(61.6 ; 79)$ & $* *$ \\
\hline P-value $\hat{\imath}$ & & $*$ & & n.s. & \\
\hline \multicolumn{6}{|c|}{ Hip circumference $(\mathbf{c m})$} \\
\hline 11 & 457 & $78.8(70.8 ; 91.2)$ & 54 & $89.1(90 ; 98)$ & $* *$ \\
\hline 12 & 279 & $82.2(74.1 ; 91.1)$ 仓ै** & 209 & $89.9(82.5 ; 102.2)$ & $* *$ \\
\hline 13 & 128 & $82.7(76.3 ; 96.5)$ 仓* & 340 & $90.8(82.7 ; 101.2)$ & $* *$ \\
\hline 14 & 42 & $83.4(75.3 ; 91.8)$ & 419 & $91.9(84.9 ; 102.3)$ & $* *$ \\
\hline P-value î & & $* *$ & & $* *$ & \\
\hline
\end{tabular}

$\diamond$ M-W (Mann-Withney Test) : horizontal (similar age groups but at different menarche stages): significant difference $\left({ }^{*} \mathrm{p}<0.05,{ }^{* *} \mathrm{p}<0.001\right)$ between pre- and postmenarche

$\Uparrow \mathrm{U}-\mathrm{W}, \mathrm{K}-\mathrm{W}$ (Kruskal-Wallis-Test): vertical (similar menarche status but at different ages): significant difference $(* \mathrm{p}<0.05, * * \mathrm{p}<0.001)$ from the previous age 
Table 3: BSCOC data: BMI and waist and hip circumference (median; 10; 90 percentile) according to pre-, recent and post-menarche per age group

\begin{tabular}{|c|c|c|c|c|c|c|c|}
\hline & $\mathrm{N}$ & $\begin{array}{l}\text { Pre-menarche } \\
\text { (median; } 10 ; 90 \text { percentile) }\end{array}$ & & $\begin{array}{l}\text { Recent menarche } \\
\text { (median; 10; } 90 \text { percentile) }\end{array}$ & $\mathrm{N}$ & $\begin{array}{l}\text { Post-menarche } \\
\text { (median; 10; } 90 \text { percentile) }\end{array}$ & $\begin{array}{l}\text { P-value } \\
\leftrightarrow\end{array}$ \\
\hline \multicolumn{8}{|c|}{$\begin{array}{ll}\text { Age } & \text { BMI }(\mathrm{kg} / \mathrm{m} 2)\end{array}$} \\
\hline 11 & 279 & $17.7(15.2 ; 22.4)$ & 20 & $20.8(16.2 ; 25.6) \Leftarrow * *$ & 14 & $19.6(18 ; 24.4)$ & $* *$ \\
\hline 12 & 251 & $17.7(15.3 ; 21.7)$ & 77 & $19.7(17.3 ; 23.3) \diamond * *$ & 102 & $20.3(17.6 ; 24.1)$ & $* *$ \\
\hline 13 & 162 & $17.9(15.6 ; 21.9)$ & 97 & $19.4(17 ; 22.8) \Leftarrow * *$ & 349 & $20.5(17.8 ; 24.8) \hookleftarrow * *$ & $* *$ \\
\hline 14 & 19 & $17.6(14.6 ; 19.8)$ & 37 & $19.2(16.5 ; 22.1) \hookleftarrow *$ & 196 & $20.5(18 ; 26.5) \hookleftarrow * *$ & $* *$ \\
\hline P-value $\hat{\imath}$ & & n.s. & & n.s. & & n.s & \\
\hline \multicolumn{8}{|c|}{ Waist circumference (cm) } \\
\hline 11 & 279 & $61.5(55 ; 75)$ & 20 & $70.5(61 ; 83.8)$ ๘** & 14 & $68.8(64 ; 82.5)$ & $* *$ \\
\hline 12 & 251 & $62(55 ; 72.8)$ & 77 & $66(61 ; 75) \hookleftarrow * *$ & 102 & $67(58 ; 79)$ & $* *$ \\
\hline 13 & 162 & $63(55.3 ; 71)$ & 97 & $66(58 ; 75) \hookleftarrow * *$ & 349 & $68(59 ; 80) \hookleftarrow *$ & $* *$ \\
\hline 14 & 19 & $62(56 ; 72)$ & 37 & $66(58 ; 78) \hookleftarrow *$ & 196 & $68(59 ; 83.3)$ & $*$ \\
\hline P-value $\hat{\imath}$ & & n.s & & n.s & & n.s & \\
\hline \multicolumn{8}{|c|}{ Hip circumference $(\mathbf{c m})$} \\
\hline 11 & 278 & $78(70 ; 89)$ & 20 & $86(76.2 ; 97.7) \hookleftarrow * *$ & 14 & $88(81.5 ; 96)$ & $* *$ \\
\hline 12 & 251 & $81(72 ; 89)$ 仓 $* *$ & 77 & $85(79.2 ; 93.2) \hookleftarrow * *$ & 102 & $88(81 ; 95) \hookleftarrow *$ & $* *$ \\
\hline 13 & 162 & $81.5(76 ; 90)$ 仓* & 97 & $86(79.8 ; 93.2) \hookleftarrow * *$ & 349 & $90(82 ; 99) \hookleftarrow * *$ 仓* & $* *$ \\
\hline 14 & 19 & $81(74 ; 90)$ & 37 & $86(80 ; 92.4) \hookleftarrow *$ & 196 & $90(83 ; 101) \hookleftarrow * *$ & $* *$ \\
\hline P-value i & & $* *$ & & n.s. & & n.s. & \\
\hline
\end{tabular}

$\hookleftarrow$ M-W (Mann-Withney Test) : horizontal (similar age groups but at different menarche stages): significant difference $(* \mathrm{p}<0.05, * * \mathrm{p}<0.001)$ between pre- and postmenarche

M-W, K-W (Kruskal-Wallis-Test): vertical (similar menarche status but at different ages): significant difference $(* \mathrm{p}<0.05, * * \mathrm{p}<0.001)$ from the previous age 
